\title{
Editorial
}

\section{Media and Communication in Europe: Babel Revisited}

\author{
Agnes Inge Schneeberger \\ Katharine Sarikakis
}

THIS IS AN IMPORTANT MOMENT IN TIME IN THE RELATIONSHIP BETWEEN EUROPEANS and the(ir) European Union. It is characterised by renewed attempts of communication, polity building and democratisation, largely located in the realms of institutional politics, but also by scepticism, resistance and counter-reflection by its citizens and even search for identity on behalf of both the EU and its peoples. It is also the appropriate time for students of European affairs and communication studies to reevaluate, review and ask anew questions around the relationship between institutional structures, elites and their aims and the people of the European Union, their own expectations and self-reflection. This special issue on media and communication in Europe seeks to explore a range of angles through which the understanding and experiencing of the EU is mediated. Communication between citizens and EU institutions has proven significant for the future of Europe: a politicised, cultured and cosmopolitan populace is expecting more or different from its supranational polity than it is receiving. The demands for further transparency and openness are central in the quest for legitimacy of an EU of 27 member states. Although communication is by no means the only remedy to a perceived or real democratic deficit, it is a key factor in building bridges between citizens and the EU through informing and engaging European citizens and fostering a sense of belonging.

The formation of an EU identity is seen as a necessary condition in the development of a political and cultural polity that surpasses its initial economistic raison d'être. Activities of the EU in the cultural field since the mid 1970s have become a catalyst for the creation of a European identity. Examples of these activities include the "Declaration on European Identity" in 1973, the agreement of the European heads of state in 1974 to study the special rights of citizens of the European community and the ad hoc committee on a People's Europe, chaired by the Italian MEP Pietro Adonnino, promoting citizen rights, culture and more factual information for European citizens in 1988. Since then the EU has introduced several EU symbols, such as the EU passport, the Euro currency, Europa day and the EU flag, in order to provide visuals and rituals common for its peoples. These cultural symbols are considered helpful in fostering a European identity.

However, times of alleged crisis have put issues of communication firmly on the agenda of EU institutions. Critical public opinion polls and negative referenda on the Treaty establishing a Constitution for Europe in France and the Netherlands in 2005 and recently on the Treaty of Lisbon in Ireland have prompted EU institutions to reevaluate their communication with the European publics. These "No" votes were a clear statement of citizens' sentiments towards the current pace and direction the EU is taking and have prompted a rethinking of institutional communication strategies. To 
many, the voice of the people says no to an elite-driven Babel: a Europe without its peoples is not a people's Europe.

Certainly, communication has become an increasingly important issue within EU institutions in this decade. Measures such as the creation of a General Directorate for Communication and the implementation of an Information and Communication Strategy for the European Union have lead to the development of a professionalised relationship with media and journalists to support the flow of information from institutions to the media and the European public. After the disappointing referenda, an improved information flow has been advanced from informing citizens to engaging them into a dialogue. This turn to reconnect with citizens has found expression in Plan D for Democracy, Dialogue and Debate which was introduced to initiate debate about the future of Europe after the negative referenda and marked a starting point for a long-term democratic reform process. Communication technologies, particularly the Internet, have facilitated the access to and dissemination of information from EU institutions. With the advancement of the Internet from accessing information to creating content and participating in online fora, EU institutions are also facing increasing pressure to adjust. The range of possibilities offered by ICTs raises expectations for EU institutions to keep up with the technical opportunities and actively engage with European citizens. While EU decision making processes are complex, lengthy and often incomprehensible to the ordinary citizen, technology demonstrates the possibility for quick input from a large number of people. This contradiction is expressed in attempts by EU institutions to engage citizens through feedback provision, but to fail to process the volume of input and to integrate it in the decision making process. In the case of the EU online discussion forum "Debate Europe", which was set up in the period of reflection after the negative referenda, contributions are merely summarised in an overview. Citizens are left wondering what a dialogue means, who listens to their feedback and what it leads to.

This JCER special issue offers a unique collection of research articles that address key challenges to the issue of 'communicating Europe'. The works in this issue address the role of new communication technologies for democratic processes and institutional legitimacy, the interpretation and status of a European identity and sense of belonging and the realisation of Europe's cultural diversity through minority language protection. They help us understand the mechanisms that connect mass media, identity formation and cultural diversity to the institutional legitimacy and future of the EU.

Guest author Michael Bruter critically examines methodological shortcomings and conceptual challenges to understand and measure European identity and proposes a reinterpretation of popular assumptions about Euroscepticism, democratic fatigue and the EU legitimacy crisis. Bruter argues that a strongly emerging (not the lack of) European identity is responsible for citizens' expressions of dissatisfaction with the EU and should be seen as a critique 'from the inside' that is by those already feeling 'European' enough to care. While this insider perspective accepts European integration as a reality, citizens now judge specific policies and reforms with increased scrutiny - as European citizens. Bruter's analysis proposes new ways of examining the ways in which European citizens relate to the polity. He concludes that revising old instruments to measure European identity is necessary to properly capture and understand what citizens want from a democratic Union.

Petra Huyst explores EU perceptions and the meaning of European identity among young Flemish people. Her qualitative study combines metaphor analyses, focus groups and multiple choice questions, forming a creative approach to counterbalance dominant quantitative mass public opinion surveys and enhances existing theoretical discussions. Animal names attributed to the EU, ranging from beaver, chameleon to butterfly, reveal contrasting perceptions and new ways of expressing images of the EU. Huyst's study results highlight the importance of different contexts for identity constructions, the coexistence of parallel identities and individual interpretations of 
perceptions of the EU which illustrate the complex processes involved in European identity formation.

In the third article Aline Sierp picks up the debate about minority language protection and the role of the media for keeping minority languages alive. Her analysis focuses on the Italian case, where twelve officially recognised languages make it the country with the greatest language diversity in Western Europe. The study addresses the tensions resulting from safeguarding Europe's cultural diversity and interests of national integrity by analysing the different legislative tools of language protection on European, national and regional level. A comparison of the cases of Arberesh-, Friulian-, and German-speaking minorities reveal discrepancies between the legal framework and implementation of provisions in the media sector. Sierp's study proposes a greater commitment of state institutions, public broadcasting companies and minorities themselves to help preserve Europe's cultural diversity.

In their work Giuditta Caliendo and Antonella Napolitano explore the EU's communication policy and the ways it is used to foster consensus and create legitimacy to support political actions. The EU enlargement period from 2004 to 2007 serves as a case to illustrate changes in the polity's communication strategy in times of declining public support. An analysis of textual and visual formulations in official EU enlargement documents reveals a shift from informative content to a more promoting communication style as a form of a consensus-building strategy. The study concludes that the EU's communication strategy has been transformed under the pressure of declining public support. It has adopted a counter-strategy that portrays EU enlargement as a necessary, positive and therefore legitimate step. Their findings demonstrate the rising importance of legitimacy in Union-to-citizen communication to justify controversial political actions and strengthen a sense of belonging.

In her contribution, Asimina Michailidou raises important issues about the role of the Internet for citizens' participation and communication with EU institutions. Her study focuses on the impact of new communication technologies on the EU's communication strategy. Her findings, comprising an EU document and website analysis, elite interviews with EU officials and an Internet survey, show that the EU's communication has shifted from simple one-way information to two-way communication between citizens and the EU. Michailidou argues that despite attempts of EU institutions to implement this public dialogue via the Internet, arising problems relating to different inter-institutional conceptions of public communication and the practical handling of citizens' feedback have not been solved yet. She concludes that it is up to the EU institutions to decide how seriously they want to commit to participatory democracy.

The final contribution consists of a review of four recent publications on media and democracy in Europe, by Patrick Bijsmans, Asimina Michailidou and Oisín Tobin. This includes a monograph on European broadcasting law and policy and three edited books, the first one on the role of communication and media technologies in the democratisation of an expanding European Union (Carpentier et al. 2007), and the second and third one on European media governance on regional, national and EU level (Terzis 2007; 2008). All three reviewers offer precise overviews and discursive scholarly evaluation of these books, discussing their strong and weak points and identifying the appropriate target audiences.

The origins for this special issue are to be found at the UACES Student Forum Conference in April 2007 at Nottingham University. At this conference the JCER and the UACES Student Forum Specialist Study Group "Media and Communication in Europe" began the production of this special issue. The Specialist Study Group is a UACES funded network bringing together PhD students and young researchers working in interdisciplinary areas relating to media and communication in Europe. 
The editorial team would like to thank all participants and contributors of the first editorial meeting and the preparatory workshop who actively participated and enriched discussions and the outcome of both events with their engagement and considerate feedback. We would also like to thank UACES for their generous financial support for the Specialist Study Group, the Institute of Communications Studies at the University of Leeds and the Centre for the Study of Ethnicity and Citizenship at the University of Bristol. Further we would like to thank Daithí Mac Sithigh for his professional collaboration and competent work as the editor for book reviews. We would also like to thank the referees for their comprehensive reviews and helpful comments on the articles included in this special issue.

Finally, very special thanks goes to Eamonn Butler for his inspiration and constant support to initiate and realise this special issue, for his great advice, and for his exceptional dedication to the editing of this special issue beyond any limits.

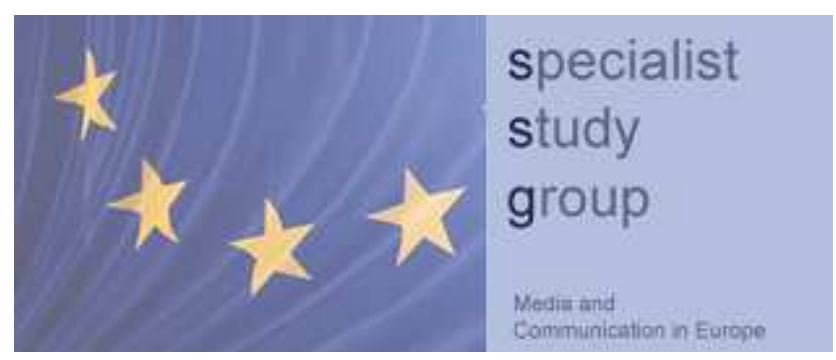

